\title{
Barriers to the Implementation of Green Chemistry in the United States
}

\section{Citation}

Matus, Kira J. M., William C. Clark, Paul T. Anastas, and Julie B. Zimmerman. 2012. Barriers to the Implementation of Green Chemistry in the United States. Environmental Science \& Technology, published online, September 10, 2012.

\section{Published Version}

http://dx.doi.org/10.1021/es3021777

\section{Permanent link}

http://nrs.harvard.edu/urn-3:HUL.InstRepos:9639957

\section{Terms of Use}

This article was downloaded from Harvard University's DASH repository, and is made available under the terms and conditions applicable to Other Posted Material, as set forth at http:// nrs.harvard.edu/urn-3:HUL.InstRepos:dash.current.terms-of-use\#LAA

\section{Share Your Story}

The Harvard community has made this article openly available.

Please share how this access benefits you. Submit a story.

Accessibility 


\section{Policy Analysis}

\section{Barriers to the Implementation of Green Chemistry in the United States}

Kira J.M. Matus, Paul T. Anastas, William C. Clark, and Julie Beth Zimmerman

Environ. Sci. Technol., Just Accepted Manuscript • Publication Date (Web): 10 Sep 2012

Downloaded from http://pubs.acs.org on September 18, 2012

\section{Just Accepted}

"Just Accepted" manuscripts have been peer-reviewed and accepted for publication. They are posted online prior to technical editing, formatting for publication and author proofing. The American Chemical Society provides "Just Accepted" as a free service to the research community to expedite the dissemination of scientific material as soon as possible after acceptance. "Just Accepted" manuscripts appear in full in PDF format accompanied by an HTML abstract. "Just Accepted" manuscripts have been fully peer reviewed, but should not be considered the official version of record. They are accessible to all readers and citable by the Digital Object Identifier (DOI®). "Just Accepted" is an optional service offered to authors. Therefore, the "Just Accepted" Web site may not include all articles that will be published in the journal. After a manuscript is technically edited and formatted, it will be removed from the "Just Accepted" Web site and published as an ASAP article. Note that technical editing may introduce minor changes to the manuscript text and/or graphics which could affect content, and all legal disclaimers and ethical guidelines that apply to the journal pertain. ACS cannot be held responsible for errors or consequences arising from the use of information contained in these "Just Accepted" manuscripts. 


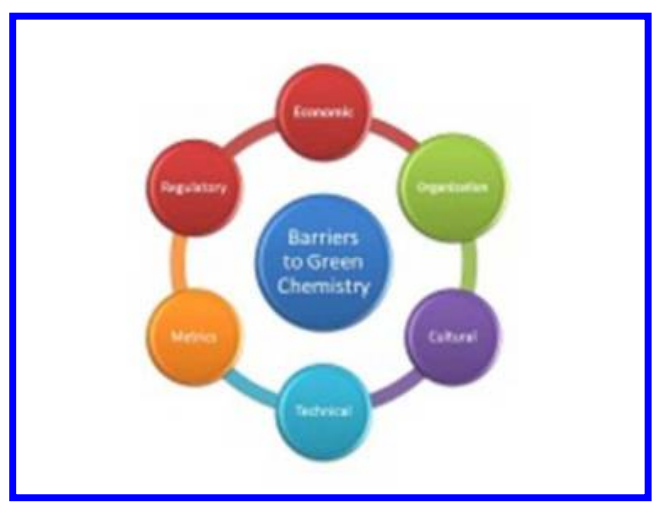

$63 \times 47 \mathrm{~mm}(96 \times 96$ DPI $)$ 


\title{
Barriers to the Implementation of Green Chemistry in the United States
}

\author{
Kira J.M. Matus ${ }^{*}$, William C. Clark ${ }^{\dagger}$, Paul T. Anastas ${ }^{*}{ }^{\S}$, Julie B. Zimmerman ${ }^{* *}, \neq$
}

\begin{abstract}
:
This paper investigates the conditions under which firms are able to develop and implement innovations with sustainable development benefits. In particular, we examine "green chemistry" innovations in the United States. Via interviews with green chemistry leaders from industry, academia, NGOs and government, we identified six major categories of challenges commonly confronted by innovators. They are: (1) economic and financial, (2) regulatory, (3) technical, (4) organizational, (5) cultural and (6) definition and metrics. Further analysis of these barriers shows that in the United States,

* Department of Government, London School of Economics and Political Science

$†$ Sustainability Science Program, John F. Kennedy School of Government, Harvard University

$\ddagger$ School of Forestry and Environmental Science, Yale University

${ }^{\S}$ Chemistry Department, Yale University

** Department of Chemical and Environmental Engineering, Yale University
\end{abstract}


two elements of these that are particular to the implementation of green chemistry innovations are the absence of clear definitions and metrics for use by researchers and decision makers, as well as the interdisciplinary demands of these innovations on researchers and management. Finally, we conclude with some of the strategies that have been successful thus far in overcoming these barriers, and the types of policies which could have positive impacts moving forward.

\section{Introduction}

Over the years, the cumulative number of regulations to which an American chemical firm must comply has increased dramatically. (1) Within the chemical industry, there is increased recognition of the need to deal with the challenges of sustainability as a strategy for moving out ahead of anticipated future regulation. One strategy has been the development green chemistry. (2) Green chemistry, along with the complimentary fields of green engineering, industrial ecology, and sustainability science represent examples of the critical emerging disciplines necessary to realize this goal. Each of these disciplines/ meta-disciplines works at different scales and with different focus areas to make fundamental contributions to advancing sustainability. Green chemistry, however, is one of the most fundamental of these fields in that it focuses on the molecular level to design chemicals and materials to be inherently non-hazardous. In theory, firms that can achieve minimally hazardous processes and products would eliminate, or significantly reduce, their regulatory burden.

The challenge of promoting greater adoption of green chemistry innovations is substantial because green chemistry is an emerging disruptive technology (3) embedded in a complex scientific, political, regulatory, economic, industrial and cultural framework. Innovations in green chemistry are innovations in a large system that spans borders between nations, between industries, and between scientific disciplines. Thus there is a need for research into the underlying causes of the barriers to the implementation of green chemistry technologies in the United States, with a view towards using its findings to inform the design of future policies. 


\section{A. Background and History of Green Chemistry}

Green chemistry is described in detail in the "12 Principles of Green Chemistry." (2) These principles are a tool for translating the goal of reducing negative impacts into an operational method for doing chemistry. These Twelve Principles have become the standard for green chemistry research and practice. They address issues of health, safety and the environment, including the efficient use of energy and materials. They encompass a multi-disciplinary, lifecycle perspective for chemists doing chemistry. They are, in many respects, a design framework at the molecular level, which, ideally would result in chemicals that are "benign by design." Benign chemicals that reduce risk by eliminating hazard (in production and in use) would allow firms to escape from the pattern of increasing regulation, since inherently safe chemicals would not need to be regulated.

While the benefits of green chemistry have been and continue to be demonstrated across the chemical enterprise, its widespread penetration and implementation has been impeded by its fundamental and disruptive nature. Current estimates put the share of green chemistry products in the chemical sector at about $1 \%$. (4) This is not unexpected; innovations are often difficult to implement, especially in mature, established industries like the chemical industry.

For green chemistry, there are theoretical and empirical reasons to support the idea that the challenges to implementation differ from innovation more generally. First, we would expect that the market acting alone would underprovide these particular innovations. This is because of the public, as well as private benefits that these technologies deliver. Empirically, green chemistry is also technically demanding. Development and implementation requires the use of multiple scientific and engineering disciplines, as well as an understanding of toxicology and environmental science. Green chemistry requires the ability to analyze trade-offs between different environmental and health impacts, while also maximizing technical performance and profits. The interdisciplinary knowledge and range of skills needed to make 
many of these technologies commercially successful is not typical of existing organizational structures in either the research or industrial sides of the chemical enterprise.

In order to identify and analyze the barriers to the implementation of green chemistry, we chose to pursue a combination of in-depth qualitative interviews and a multi-stakeholder workshop, in order to elicit the experiences of experts in the field. First, in 2006 we interviewed ten experts in the field of green chemistry $^{\dagger \dagger}$. All of these experts had experience translating research into commercial activities and knowledge of the barriers that are present for the implementation of green chemistry technologies. All of the interviews were qualitative, semi-structured, and based on a common interview protocol. This kind of qualitative interviewing process is conversational by nature, and as such, the focus and order of the topics covered differed from interview to interview. It is based on a set of topics to be considered, as opposed to a more formal set of survey questions ${ }^{\dagger+}$. (5) These interviews formed the basis for an initial set of barriers to adoption, which were presented to a group of approximately thirty interested and qualified individuals from industry, academia, government, and non-governmental institutions ${ }^{\mathrm{i}}$ at a workshop in 2007. This larger, multi-stakeholder group refined the barriers based on their experiences in the field, and the different perspectives that they represented. Both the interviews and the workshop were conducted under an agreement of non-attribution. Geographically, all of the research was focused on green chemistry occurring in the United States, as opposed to issues faced in other parts of the world. Because green chemistry penetration is relatively limited in the chemical industry, we chose to focus on the subset of individuals with knowledge and experience in the field, in order to be sure to capture the phenomena of interest. While this set of individuals is not representative of the chemical industry, NGOs, and regulators as a whole, they did span a broad set of the organizations active in this particular field.

\footnotetext{
$\dagger \dagger$ See Supporting Information

$\$$ See Supporting Information
} 


\section{The Barriers to Green Chemistry Implementation}

Analysis of the impediments to Green Chemistry is an important for understanding its potential for widespread adoption. There has been other research on the nature of the barriers that typically impede the implementation of green chemistry. (6-10) Our initial hypothesis was that candidates for important barriers include key regulatory impediments, knowledge impediments, challenges with metrics and impediments that are the result of the institutions, culture and infrastructure particular to the chemical sector. While many of these candidate barriers appear to be perfectly reasonable, there was a need for a deeper investigation into the dynamics present in this particular innovation system ${ }^{\S}$. The development of a more comprehensive framework of the green chemistry innovation system (11) also provides a way to develop an analytical understanding of where, within the system, these key barriers occur, what resources they impact, and which stakeholders are involved. (12)

Through interviews and the workshop, a set of common barriers emerged. Table 1 shows the list of major barriers, and the number of the initial pool of interviewees who identified them as key challenges. Each barrier type will be presented in more detail below. Given the semi-structured nature of the interviews, the failure to mention particular barrier during the course of an interview does not necessarily indicate a divergent opinion. In fact, there was almost no overt divergence of views on these topics. Instead, the variation appears to be on which trends and issues are considered the most important by each individual interviewee. One of the major tasks of the workshop was to capture the specific elements of each barrier type, and to probe for any major divergence of opinion on inclusion of particular barriers and any that might have been missed due to composition of the initial interview set. 
Table 1- Frequency of Interviewee Identification of Barriers $(\mathrm{N}=10)$

\begin{tabular}{|l|c|}
\hline Barrier to Green Chemistry Adoption & $\begin{array}{l}\text { Number of } \\
\text { Interviewees } \\
\text { Reporting } \\
\text { (N=10) }\end{array}$ \\
\hline Economic and Financial: Costs, incentives, and markets & 5 \\
\hline Regulatory: Uncertainty, timing, disincentives & 5 \\
\hline Technical: Expertise, education, training scientific and engineering issues & 5 \\
\hline Organizational: Intra-firm, and firm-academic & 6 \\
\hline Definition and metrics: unavailable, or difficult to operationalize & 6 \\
\hline Cultural: Awareness, educational curriculum, priorities, attitudes & 9 \\
\hline
\end{tabular}

In Section 3, we compare these green chemistry-specific barriers to similar barriers to innovation generally from the literature. This process disaggregates general barriers to innovation from those that are the result of the details of the green chemistry system. This, in turn, is a useful step in understanding and developing effective policy approaches to green chemistry innovations in particular, and innovations for sustainable development more generally.

\section{A. Framing the Barriers}

What are the barriers that slow or prevent the implementation of green chemistry? In particular, which of these barriers are the most particular to the chemical enterprise, as opposed to the more general problems associated with implementing technical innovations in well-established industries?

The research indicated that there are a complex set of intertwined issues that act as barriers to the effective implementation of green chemistry within the chemical enterprise. In the United States, they broadly fall into the categories of economic and financial, regulatory, technical, organizational, cultural, 
and even definition and measurement. These categories themselves have significant interactions and overlaps between them.

The sectors of industry that fall under the chemical enterprise umbrella are both large and diverse. They range from pharmaceuticals to textiles, from pesticides to paper, from petroleum products to specialty chemicals, plastics, and just about everything in-between. It is not unusual for a company that specializes in a consumer product like sporting goods to evaluate its processes and discover that it is also in the business of large-scale chemical production. The variety and ubiquity of the use and production of chemicals within industry creates an underlying challenge. Many firms that fall into the chemical umbrella may not see themselves as such, which makes the dissemination of information to these arenas much more difficult.

Furthermore, diversity within industry extends beyond product lines, but also includes the particular kinds of barriers that different firms face when they decide to implement green chemistry. There is a huge variety of technical knowledge within the industry, much of it highly contextual. There are also very different experiences with regulations. In some sectors, this can mean the need to recertify pharmaceutical products, while in others, no action at all may be required. This is just one aspect which affects how and where green chemistry is easy (and difficult) to implement. Diversity in particular firm cultures, organizational structures, and financial situations throughout the chemical enterprise also impact implementation. This means that any particular sector, or even any particular firm, may find itself facing a unique group of barriers which complicates learning and knowledge transfer to take place between firms and across sectors.

Many of the sectors in the industry are highly intertwined, which means that firms within the chemical enterprise occupy a variety of positions along the supply chain, from primary production (i.e. petrochemicals) all the way to consumer products. Some firms face demand from the consumer market, others are focused on industrial and business to business (B2B) markets, and some firms may deal with both. The needs of these very different markets add to the complexity of evaluating potential barriers to 
green chemistry. Despite this diversity, there are many barriers which appear to be common across large parts of the chemical enterprise.

\section{B. The Barriers}

Each of the major barriers are elaborated below, based on information reported during the interviews and the workshop discussions.

\section{Economic and Financial Barriers}

Within the chemical enterprise, a new product or process based on green chemistry must meet two criteria- economic and environmental performance. The product or process must not only represent an improvement for health and the environment, but it must also be more profitable, without sacrificing efficacy or quality. In the case of an existing product, changes in the production process or formulation must represent enough of a potential cost savings to out-weigh upfront costs. Pfizer has saved millions of dollars to date from Presidential Green Chemistry Award winning changes to the process to synthesize sertraline, the active ingredient in Zoloft. The resulting revenue increase was enough to overcome the costs, which went beyond capital investment and included all of the costs associated with the timeconsuming process of recertifying the drug with the FDA. (13) But a small decreases in costs of waste, marginal efficiency improvements, or implementation of less dangerous processes may not be enough to justify large investments, especially when exact savings are uncertain or hard to quantify.

There are other financial barriers. Many chemical enterprises are highly capital intensive, and firms will be reluctant to abandon their previous investments. The costs of shuttering an old, inefficient plant can be very high, leaving firms without the resources to then re-invest in new technologies. One study a contract fine chemical producer uses large reactors, even for making small batches of pharmaceutical API's. This requires large quantities of waste solvent, among other inefficiencies. This is the kind of case where greener processes could easily be deployed, but for the fact that firms find themselves tied to the facilities 
at hand. (14) Depending on the sector, many operations may not enjoy high-enough margins to overcome the financial and economic barriers to change.

\section{Regulatory Barriers}

The significant growth in environmental regulations over time has had an important impact on the chemical enterprise. And given the increasing globalization of the chemical enterprise, many firms must cope with different regulations in each of the nations where they produce and sell their products. While green chemistry is interested in reducing inherent risk through the reduction of hazard, most environmental, health and safety regulations focus instead on reducing risk through reductions in exposure. This means that many firms find themselves in situations where they must use their resources on mandated actions and end-of-pipe technologies, instead of investing in research and development into inherently safer products and processes. In 2005, chemical manufacturing spent more than any other industrial sector on pollution abatement. (15) This illustrates the results of a regulatory focus on risk control, rather than risk prevention, can be a serious barrier. This distribution of costs at least partly reflects a regulatory focus on risk control, rather than risk prevention. Under control-oriented regulation, firms have little incentive to invest in prevention, and may be forced to divert resources to control instead.

There are also regulatory barriers that are product sector specific. If a pharmaceutical company wishes to change certain parts of its method of production for a product on the market in the United States, it must undergo a time-consuming and expensive recertification process with the FDA. If a company develops a pesticide that is safer, or produced in a less hazardous or more environmentally friendly manner than one in current production, it must go through the process of registration with the EPA under FIFRA. New chemicals that may replace harmful PBT's or carcinogens must be registered with the EPA under TSCA. These regulations, while meant to protect, do not offer any incentives for greener alternatives (such as a fast-track for processes that provide environmental or health benefits) and often take enough time, money, or both, to create a significant barrier to the implementation of green chemistry. 
Another example of regulatory barrier pertains to government preferred procurement .Even regulations meant to incentivize green innovation can become problematic. Shaw Carpet introduced its EcoWorx carpet tiles in 1999. One of the advantages of this new carpet material is that both the backing and facing are recyclable into new tiles. However, initially, the tiles are made up of new (virgin) materials. This became an issue due to the fact that government environmentally preferred procurement status is based on total current recycled content. So even though with EcoWorx, less waste goes to landfills, it was at a disadvantage in terms of government procurement. (16) EcoWorx is an example of the barrier to new green chemistry innovations that result from well-intentioned environmental regulations.

Finally, there are financial regulations that can also create a barrier. Many of these involve details of the accounting systems, and how and when a company can write-off old infrastructure. There are also financial complexities that come from the regulations governing the liability of firms for the land where their facilities are cited, should any health or environmental problems that result from these facilities arise in the future. Even if companies are able to shutter old plants, they face a significant potential future financial liability (such as Superfund), that makes it much more attractive to continue with the status quo than to make investments in new infrastructure.

\section{Technical Barriers}

The science behind green chemistry is often complex and multi-disciplinary. While the underlying chemistry has made great progress, there are many reactions and processes for which greener substitutes remain unknown. Even where academic or industrial research has devised a new reaction or synthetic pathway to a given chemical, this knowledge may not be readily available to the chemists within industry. Some of it remains in the firms that develop it, protected as trade secret for competitive advantage. Some of it is buried within the vast chemical literature, and may not even be labeled anywhere as being a 
"green" alternative. As of yet, there is no formal collection and dissemination, large-scale green chemistry database, or comprehensive reference.

When tools are generated by one firm, or within one industry, they can be very difficult to implement elsewhere. S.C. Johnson, Inc. has been very successful in its implementation of its Greenlist ${ }^{\mathrm{TM}}$ program. Greenlist $^{\mathrm{TM}}$ is an internal tool that rates every product by its environmental and health impacts. It helps scientists design newer, greener products, and also improve on existing ones. It also provides a quantitative metrics that can be used by management regarding performance. But the very flexibility to absorb detail and context that makes it effective also makes it very difficult to transfer to other firms. It requires a significant technical effort to adjust it for the products of other formulators, and even more fundamental adjustment would be required if it were to be transferred to other sectors, especially those that are involved in the production, as opposed to the formulation, of chemical products.

The number of disciplines involved in green chemistry also creates a technical barrier. Organic chemists typically do not have a working knowledge of toxicology, chemical engineering, or ecology. Similarly, toxicologists are not trained as synthetic chemists, and the engineers usually do not have extensive knowledge of environmental systems. This makes it difficult for chemists to anticipate, or take into account, the potential downstream effects of a product or a synthetic pathway, unless they are provided with a tool-set to aid them in a more systematic evaluation. The lack of a broader technical background in the training of chemists, including the ability to think on a more global, systems level, has emerged as an important barrier to the integration and implementation of green chemistry within industry. In some cases, a firm's existing expertise is insufficient. When BASF started developing bio-based polymers, they discovered that their polymer scientists did not have the required experience working with bio-based feedstocks. The solution in this case was to partner with a biotechnology startup. (17) But these kinds of expertise gaps can pose significant technical challenges.

A final technical barrier is the result of data and information gaps. Nike has developed Nike Considered, which it uses to measure the sustainability of its products. This required chemical data from suppliers. Nike encountered two challenges. First, they found that suppliers may not have, or can be 
unwilling to share, information about the chemicals used in production processes. Secondly, for many substances, hazard characteristics remain unknown. (18) There are many of these sorts of gaps in the knowledge base that create barriers to implementation.

\section{Organizational Barriers}

Within firms, the implementation of green chemistry can run into problems that are the result of the organization's structure. A division may be reluctant to change to a greener production process that may produce costs for their own bottom-line, even if the results benefit the firm as a whole, since this could negatively impact evaluations of the division's performance. The same problem can occur even more locally, when a particular facility is reluctant to implement a change which would be good for a division overall, but that would be locally costly.

There can also be occasions where the development of a greener product in one part of a company will hurt the sales of another product, leading to conflicts and difficulty in implementation. These kinds of organizational clashes are especially likely to occur if the overall business plan and evaluation structure does not explicitly include environmental and health metrics.

Another kind of organizational barrier can occur when the "champions" of a greener product or process are not in positions of power. If support does not exist at the very top, then implementing green chemistry becomes less of a priority, and it is difficult to secure the necessary resources for implementation. Like any other project, green chemistry can fall prey to the power struggles within any given company. Besides the importance of support at the top of the firm, it is also important for there to be buy-in from those who actually are in charge of the research and production processes. The absence of a common environmental goal across the organization can be a significant hurdle to implementation.

One final organizational barrier occurs when firms develop their business models for green chemistry innovations. For example, BASF's bioplastics business has been based out of a relatively small R\&D 
division, and subject to changing managerial opinions on the worth of the products to the business. (17) As opposed to some of its competitors in the biopolymers market, specifically Dow Chemical, it has chosen to concentrate on a smaller, niche market, instead of building company-wide innovation goals and developing broader, and even new markets. (17)

\section{Cultural Barriers}

Within firms, the regulatory community, academia, and even the general public, there are barriers that could best be classified as cultural. One of the most important of these is awareness. While green chemistry has made significant progress, it is unknown or misunderstood by a large number of chemists. It is not part of the standard curriculum in most schools, although this is beginning to change. And while training is low among chemists, many managers lack even basic awareness of the concept, and its business potential. People whose jobs revolve around sales, marketing, and operations have even less exposure to the concepts and potential benefits of green chemistry. Some may harbor misconceptions regarding the actual nature of green chemistry, and may consider it to be just greenwashing, or a part of the "environmental agenda," as opposed to a set of practices grounded in rigorous science. Or, they just may have no idea that the science itself is available, and could have important benefits.

There are also cultural barriers that are the result of previous experiences with the environmental movement. These include, from the corporate standpoint, the idea that all environmentally friendly changes are expensive and not particularly worthwhile. This is a legacy of the largely command-andcontrol policies typical of environmental regulation through the 1980's, which often mandated costly technologies. $(19,20)$ For the general public, there has been a variety of often less than successful "green" products over the years. In interviews and the workshop, participants spoke of a lingering 
perception among some consumers that products labeled as "green" are more expensive and less effective, which lowers demand and limits the effectiveness of green as a marketing strategy.

There are also cultural barriers that arise from the separation of academia from industry. Academia is concerned with providing an education that produces first-rate chemists, and the definition of what that education includes have remained remarkably constant since the end of World War II. Changes in chemical education have been difficult, and incorporation of green chemistry into the curriculum, while gaining ground, is hardly universal. Academia is also focused on its own particular research goals, which are not necessarily the same as the research agendas that would be useful to industry. The differences between the research interests of academics, whose careers depend on publications in peer-reviewed journals and their image in the academic community as serious researchers, can be very different from the research interests of chemists within industry. These chemists are concentrated on particular problems which they are attempting to solve, in an arena where speed, effectiveness and cost-efficiency are important to their personal success.

Finally, there are cultural barriers within the chemical enterprise that deal with innovation more broadly. Some sectors are highly innovative, constantly rework their products and processes, and place great value on being as efficient and cutting-edge as possible. This is often the case with consumer products firms, who face a constantly shifting market demand, and must innovate to stay competitive. However, there are other sectors that are less open to innovation. The pharmaceutical industry has been confronted with its resistance to change. This has also been the case with bulk chemicals, and other sectors whose products are (or are very much like) commodities. The degree to which the culture of a sector or firm shuns innovation in general can create a significant barrier to the implementation of green chemistry.

\section{Barriers from Disagreements Regarding Definitions and Metrics}


Green chemistry, unlike many other elements of sustainability, consists of a rigorous definition and design framework, which is embodied in the Twelve Principles of Green Chemistry. (2) Nonetheless, a final important barrier emerges from questions about what exactly constitutes green chemistry. The term is often used interchangeably with chemical sustainability, and can easily be grouped in with green engineering and sustainable development in general. It is unclear to some whether green chemistry is its own branch of chemistry, like organic or physical chemistry; whether it is a method for analyzing and thinking systematically about chemistry; or whether it is something else entirely. This kind of definitional fuzziness can be both positive and negative. It has allowed for a fair amount of longitude in developing the science, but it has also led to confusion and argument about whether a given reaction, product, or process really represents green chemistry.

Part of this last problem is compounded by the absence of a metric or certification for green chemistry. Green chemistry is highly contextual, and thus open to a great deal of debate. The ability to have a process for certification, such as is found with organic food products, creates a way for firms to express to their markets that a product is more environmentally friendly by some well-defined (though possibly still contestable) measure. This could be much more difficult with green chemistry, since a careful reading of the Twelve Principles reveals that green chemistry is a process for thinking about chemistry from a systems perspective, as opposed to set of goals or standards of what makes something green.

One of the barriers that emerges from the loose definition and current lack of metrics is that it is hard to point to a given product and declare it "green." Because the Twelve Principles define a complex, multiparameter system that often involves making trade-offs between its elements, it is very difficult to create bright-line standards that would make green chemistry certification and labeling effective. The closest there is to such a system is the NSF/GCI/ANSI 355: Greener Chemicals and Processes Information Standard. This standard, developed through the multi-stakeholder ANSI process, does not certify that a process or product is "green chemistry." What it does do is set up a standardized reporting system for chemical hazard properties and process impacts. (21) This kind of reporting system is designed to help deal with many of the information and data gaps discussed in the technical barriers system. 
Multiple interviewees noted that the lack of a clear way to certify something as "green chemistry," makes harder to create support in firms, presents limits for potential marketing opportunities, and it may end up causing too much focus on debating what is "in" and what is "out," as opposed to working on the underlying science.

\section{Discussion}

\section{A. Themes}

In the United States, while there are six main barriers to the implementation of green chemistry, they appear to have two common threads. Prominent to many challenges to implementation is a dearth of information that is required to develop, implement, and analyze the new technologies. Some of the information exists but is not accessible; a significant quantity, including metrics and toxicology data, still requires more research. The shortcomings in the actual knowledge base are exacerbated by a lack of general awareness about green chemistry and sustainability more broadly. People are unaware of the value of information that they possess, or of the existence of the need for more work in key areas.

A second key theme is the challenge that emerges from the economic aspect of sustainability. Firms need markets for their products, and a way to recoup their costs if they are to stay in business. For many in the United States, regulatory requirements and significant amounts of existing physical capital increase the financial risks of developing and implementing green chemistry technologies. In some cases, a lack of understanding on the part of those in marketing, sales, and high-level decision making positions makes it easy for firms to miss out on potentially profitable opportunities. Since implementation of green 
chemistry requires that it be as economically profitable as the non-green alternatives ${ }^{* * *}$, economic barriers are just as significant as technical ones.

\section{B. Analysis: Barriers to Innovation vs. Barriers to Green Chemistry}

Many of the economic challenges of innovation for sustainable development, including green chemistry, stems from the fact that they encompass an area in which there are significant market failures at play. For green chemistry in the United States, issues arise from externalities, information asymmetries, and even the simple absence of markets. There are also more complex problems, which result from the interactions of other policies, such as economic, energy, and even trade and accounting rules, with elements of the green chemistry system. For green chemistry, the most pertinent market failures are information asymmetries, the public good aspect of the system, and interactions from other, existing policies. This is shown visually in Table 5, which presents the barriers to the implementation of green chemistry innovations in terms of their root causes (which types of market failures and interactions).

Table 2- Root Causes of Barriers

\begin{tabular}{|l||c|c|c|c|c|} 
& Public & Externalities & \multicolumn{2}{|c|}{ Natural Information } & Policy \\
& Goods & & Monopolies & Asymmetries & Interactions \\
\hline Economic and & $\mathrm{X}$ & $\mathrm{x}$ & & $\mathrm{x}$ & $\mathrm{X}$ \\
\hline
\end{tabular}

*** John Warner, presentation at $3^{\text {rd }}$ Indo-US Workshop on Green Chemistry, Delhi, India, 2008 


\begin{tabular}{|l|c|l|l|c|c|}
\hline Regulatory & $\mathrm{X}$ & & & $\mathrm{X}$ & $\mathrm{X}$ \\
\hline Technical & $\mathrm{X}$ & & & $\mathrm{X}$ & \\
\hline Organizational & $\mathrm{X}$ & $\mathrm{X}$ & & $\mathrm{x}$ & $\mathrm{X}$ \\
\hline Cultural & & & & $\mathrm{x}$ & \\
\hline Definition and & $\mathrm{X}$ & & & $\mathrm{x}$ & \\
Metrics & & & & & \\
\hline
\end{tabular}

Of these root causes, information asymmetries are especially pernicious. Green chemistry is an innovation platform that is highly knowledge intensive. It requires that large quantities of information be available to all of the actors in the system. Yet key pieces of information for decision-makers throughout the system may not be available to them. Industry has knowledge not available to consumers or regulators; academia may have access to information hidden to industry. Problems with the knowledge flow, which cause the information asymmetries, are one important aspect that policy could address.

Green chemistry also has a significant public goods aspect. Many of the benefits of green chemistry innovations accrue to society, not to the innovator. It is always difficult for an innovator to capture its full benefits. But environmental benefits accrue to the public, and so many of the barriers to implementing green chemistry arise from the problems with promoting the provision of public goods. This impacts research, regulatory and bureaucratic decision-making, and decisions about the investment of limited financial resources on the part of firms. While they may want to "do the right thing," firms also have to make sound financial decisions, and societal benefits from green chemistry do not impact their bottom line in the absence of policies that create incentives for these types of actions.

Another step in analyzing the barriers to the implementation of green chemistry is acknowledging that many overlap heavily with innovation more generally. The innovation literature indicates at least six main types of barriers that are commonly found: organizational, cultural, economic and financial, market, regulatory and path-dependence. $(7,22-31)$ From a policy perspective, this indicates that policies to 
support innovation generally, through the reduction of these barriers, are expected to have a positive impact on green chemistry.

These findings also highlight some areas where the demands of green chemistry are particular to this specific family of innovations. In the United States, the problems around definition and metrics are an element that appears to be more specific to green chemistry than innovation broadly. These barriers are part of the difficulty of establishing useful and appropriate ways of measuring indicators of sustainability, and integrating them into a business decision-making context. These metrics are not well supported within most academic and/or industrial organizations.

In the United States, a reading of the barriers as a group shows that green chemistry also runs into particular difficulty because it is "competence destroying". This means that it rewards a different set of abilities than previous technologies. (27) Green chemistry requires new approaches, and an expanded skill set on both the technical and managerial ends. For those who have built careers on the traditional way of doing work in both academic and industrial chemistry, this presents a threat to their established position. This issue appears to be nearly universal within green chemistry, due to the fact that most training and industrial experience do not reflect the broad, multi-disciplinary demands of green chemistry.

\section{Conclusions}

The barriers to the successful implementation of green chemistry are significant. Despite this, during their interviews and the workshops, participants identified some common elements that had been key to successful efforts. There are at least seven factors that, time and again, have been important to the success of green chemistry, and had helped them to overcome many of the barriers. They are

- Champions at upper and technical levels,

- Regulatory pressures,

- Availability of capital, 
- Clear benefits,

- Green chemistry metrics integrated into goals and strategy (real performance incentives),

- Market demand, and

- Supply chain pressure.

The success of leaders in the field indicates that there are a number of potential levers in the system of green chemistry innovation where policies could help alleviate some of the barriers. One area where policy can have an impact is on the creation and dissemination of information. The timeliness of information flows and the need to continually increase the base knowledge stocks are a cornerstone to successfully developing green chemistry innovations. There are a variety of potentially effective ways to address the problems that arise from informational challenges. Policy can also help reduce many of the delays in the system that prevents basic research discoveries from moving into use in technology deployment. This finding is particularly interesting, because it indicates that the first action by government should be to facilitate knowledge creation and accessibility, and not focus entirely on specific regulatory prescriptions.

Secondly, incentives are important. Investment in basic research and information is not sufficient on its own. There needs to be more training for scientists, but even more importantly, the right kinds of incentives for firms to implement technologies. This is where policies can lower many of the economic and financial barriers. Recent OECD research has suggested that policy and regulation have an impact on the development of green technologies within the chemical industry. (32) While an OECD's study has found that traditional regulation is one driver of innovation, other policies with a potential for large impact include tax incentives, access to inexpensive capital, and technical assistance for implementation. Special focus should be placed on small businesses, which face higher barriers than larger firms. Many of these smaller businesses may not have the funds or personnel to implement these technologies on their own, or even recognize themselves as part of the chemical sector, but have potential for significant health 
and local environmental benefits (i.e. auto painting, textile and paper, dry cleaners, nail salons, etc.). Policies should not prescribe particular technologies, and also should improve the access to data (including testing), to avoid costly replication of work. Attention also needs to be paid to acceptable levels of risk tolerance and a more thorough discussion of the societal acceptability of hazard.

It is important to stress that the actions of one set of stakeholders (for example, those involved with the regulatory and policy processes) can have a significant impact on barriers for all those involved. Changes to the chemistry curriculum to produce graduates with the prerequisite knowledge and skills to develop and implement green chemistry would have a significant positive impact on the technical challenges faced by industries. Policies to advance green chemistry need to be part of a larger, integrated approach. Approaching the problem piecemeal is not likely to be effective.

Furthermore, policy in this case can be thought of as being broader in scope than just traditional public policy, to include the strategic decisions and actors of players from other sectors, who can identify areas in which they are able to have an impact, and proceed accordingly. Work with a multi-stakeholder group of green chemistry experts demonstrated the types of useful, action-oriented approaches that can emerge from this framing. (33) Finally, and most importantly, the research supports the idea that policies to support innovation for sustainable development are needed in a variety of places throughout the innovation system. For this reason, policy makers need to diagnose the system before they start prescribing remedies. They need to understand what types of actions, with which groups of stakeholders will be effective at combating key barriers in different points in system. And it is these sorts of wellthought out, collaborative actions that will be needed to move the implementation of green chemistry forward, beyond the many barriers in its path. 
AUTHOR INFORMATION

Corresponding Author

*Department of Government, London School of Economics and Political Science, Houghton St., London WC2A 2AE, UK. k.matus@1se.ac.uk. +44 (0)20 71075335

\section{Author Contributions}

The manuscript was written through contributions of all authors. All authors have given approval to the final version of the manuscript.

\section{Acknowledgments}

This research has been made possible due to the generous support of:

ACS Petroleum Research Fund

ACS Green Chemistry Institute

The Belfer Center for Science in International Affairs (Harvard University)

The Roy Fellowship

The Vicki Norberg-Bohm Fellowship

And support from Kai Itameri-Kinter, Nancy Dickson, Mary Anne Baumgartner and Nora O’Neil.

This publication was developed under STAR Fellowship Assistance Agreement No. FP916883 awarded by the U.S. Environmental Protection Agency (EPA). It has not been formally reviewed by EPA. The views expressed in this publication are solely those of the authors, and EPA does not endorse any products or commercial services mentioned in this publication. 


\section{References:}

(1) Cusumano, J. A. New technology and the environment. CHEMTECH 1992, 22, 482-489.

(2) Anastas, P. T.; Warner, J. C. Green chemistry $\square$ : theory and practice; Oxford University Press: Oxford England $\square$; New York, 1998.

(3) Christensen, C. M. The innovator's dilemma $\square$ : when new technologies cause great firms to fail; Harvard Business School Press: Boston, Mass., 1997.

(4) Goodman, S. "Green chemistry" movement sprouts in colleges, companies. The New York Times 2009.

(5) Babbie, E. R. The practice of social research; Wadsworth Pub Co, 2007.

(6) Poliakoff, M.; Licence, P. Sustainable technology: Green chemistry. Nature 2007, 450, 810-812.

(7) Poliakoff, M.; Fitzpatrick, J. M.; Farren, T. R.; Anastas, P. T. Green chemistry: Science and politics of change. Science 2002, 297, 807-810.

(8) Satterfield, M. B.; Kolb, C. E.; Peoples, R.; Adams, G. L.; Schuster, D. S.; Ramsey, H. C.; Stechel, E.; Wood-Black, F.; Garant, R. J.; Abraham*, M. A. Overcoming Nontechnical Barriers to the Implementation of Sustainable Solutions in Industry. Environ. Sci. Technol. 2009, 43, 4221-4226.

(9) Wilson, M. P.; Schwarzman, M. R. Toward a new US chemicals policy: rebuilding the foundation to advance new science, green chemistry, and environmental health.

Environmental health perspectives 2009, 117, 1202.

(10) Matus, K. J. M.; Xiao, X.; Zimmerman, J. B. Green chemistry and green engineering in China: drivers, policies and barriers to innovation. Journal of Cleaner Production 2012, 32, 193-203. 
(11) Matus, K. J. Green Chemistry: A Study of Innovation for Sustainable Development, Harvard University, 2009.

(12) Matus, K. J. M.; Hutchison, J. E.; Tanguay, R. L.; Rung, S.; Peoples, R. Green Nanotechnology Challenges and Opportunities; American Chemical Society, 2011.

(13) Manley, J. B.; Anastas, P. T.; Cue Jr., B. W. Frontiers in Green Chemistry: meeting the grand challenges for sustainability in R\&D and manufacturing. Journal of Cleaner Production 2008, 16, 743-750.

(14) Scott, A. Chemical Week. March 8, 2010, p. 21.

(15) U.S. Census Bureau Pollution Abatement Costs and Expenditures: 2005; MA200; 05; U.S. Government Printing Office, Washington, DC, 2008; pp. 9-10.

(16) Segars, J. W.; Bradfield, S. L.; Wright, J. J.; Realff, M. J. EcoWorx, green engineering principles in practice. Environmental science \& technology 2003, 37, 5269-5277.

(17) Iles, A.; Martin, A. N. Expanding bioplastics production: sustainable business innovation in the chemical industry. Journal of Cleaner Production.

(18) Green Chemistry and Commerce Council Considered Chemistry at Nike: Creating Safer Products through the Evaluation and Restriction of Hazardous Chemicals Case Study for the Green Chemistry and Commerce Council (GC3); Lowell Center for Sustainable Production at the University of Massachusetts Lowell: Lowell, MA, 2009.

(19) Esteghamat, K. Structure and Performance of the Chemical Industry Under Regulation. In Chemicals and Long-Term Economic Growth; John Wiley and Sons: New York, 1998.

(20) Hoffman, A. J. From heresy to dogma $\square$ : an institutional history of corporate environmentalism; Stanford University Press: Stanford, Calif., 2001; Vol. Expand. 
(21) NSF International NSF International $\square$ : Sustainability $\square$ : NSF/GCI/ANSI 355: Greener Chemicals and Processes Information.

http://www.nsf.org/business/sustainability/product_greener_chemicals.asp?program=Susta inability (accessed August 14, 2012).

(22) Dahlman, C. J.; Ross-Larson, B.; Westphal, L. E. Managing Technological Development: Lessons from Newly Industrialized Countries. World Development 1987, 15, 759-775.

(23) March, J. G.; Simon, H. A. Organizations; Wiley: New York, 1958.

(24) Lall, S.; Pietrobelli, C. Failing to Compete; Edward Elgar Publishing, Ltd.: UK, 2002.

(25) Archibugi, D.; Pietrobelli, C. The globalization of technology and its implications for developing countries: Windows of opportunity or further burden? Technological Forecasting \& Social Change 2003, 70, 861-883.

(26) Ruttan, V. W. Technology, growth, and development $\square$ : an induced innovation perspective; Oxford University Press: New York, 2001.

(27) Tushman, M.; Smith, W. Innovation Streams, Organization Designs, and Organizational Evolution. In Managing Strategic Innovation and Change; Oxford University Press: New York, 2004; Vol. 2, p. 2.

(28) Gatignon, H.; Tushman, M. L.; Smith, W.; Anderson, P. A structural approach to assessing innovation: Construct development of innovation locus, type, and characteristics. Management Science 2002, 48, 1103-1122.

(29) Tushman, M. L.; Anderson, P. Technological Discontinuities and Organizational Environments. Administrative Science Quarterly 1986, 31, 439-465.

(30) Gavetti, G.; Levinthal, D. Looking forward and looking backward: Cognitive and experiential search. Administrative science quarterly 2000, 45, 113-137. 
(31) Anderson, P.; Tushman, M. L. Technological Discontinuities and Dominant Designs: A Cyclical Model of Technological Change. Adm.Sci.Q. 1990, 35, 604-633.

(32) OECD Inter-Organization Programme for the Sound Management of Chemicals Sustainable Chemistry: Evidence on Innovation from Patent Data; OECD Environment, Health and Safety Publications Series on Risk Management; 25; OECD: Paris, 2011.

(33) Matus, K. J. Policy Incentives for a Cleaner Supply Chain: The Case of Green Chemistry. Journal of International Affairs 2010, 64, 121-136. 